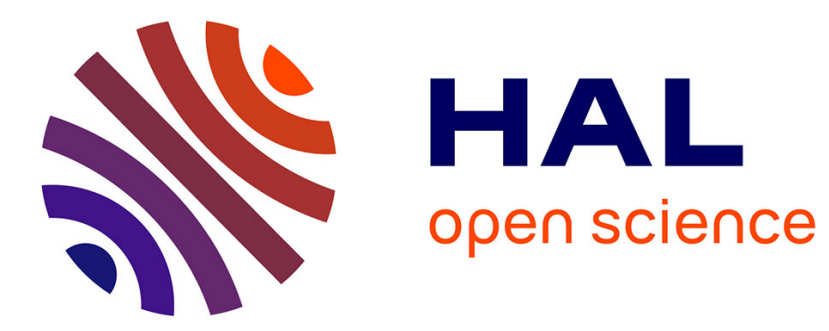

\title{
Processing of the CFOSAT -SWIM data: algorithm prototyping and simulations
}

Céline Tison, Danièle Hauser, Lauriane Delaye, Thierry Koleck, Nicolas Lamquin, Milena Planells, Flavien Gouillon, Patrick Castillan

\section{To cite this version:}

Céline Tison, Danièle Hauser, Lauriane Delaye, Thierry Koleck, Nicolas Lamquin, et al.. Processing of the CFOSAT -SWIM data: algorithm prototyping and simulations. IGARSS 2015, Jul 2015, Milan, Italy. 4 p. insu-01183441

\section{HAL Id: insu-01183441 https://hal-insu.archives-ouvertes.fr/insu-01183441}

Submitted on 12 Oct 2015

HAL is a multi-disciplinary open access archive for the deposit and dissemination of scientific research documents, whether they are published or not. The documents may come from teaching and research institutions in France or abroad, or from public or private research centers.
L'archive ouverte pluridisciplinaire HAL, est destinée au dépôt et à la diffusion de documents scientifiques de niveau recherche, publiés ou non, émanant des établissements d'enseignement et de recherche français ou étrangers, des laboratoires publics ou privés. 


\title{
PROCESSING OF THE CFOSAT-SWIM DATA: ALGORITHM PROTOTYPING AND SIMULATIONS
}

\author{
C. Tison(1), D. Hauser(2), L. Delaye(2), T. Koleck(1), N. Lamquin(3), M. Planells(1), F. Gouillon(1), P. \\ Castillan(1)
}

(1) CNES, 18 avenue Edouard Belin, 31400 Toulouse, France

(2) CNRS, LATMOS/UVSQ, 11, boulevard d'Alembert, 78280 Guyancourt, France

(3)ACRI-ST, 11, boulevard d'Alembert, 78280 Guyancourt, France

Celine.tison@cnes.fr ,+33561282404

\begin{abstract}
This paper presents the under-going development of the ground segment algorithms of the SWIM instrument. SWIM is a wave scatterometer which will be embarked on the Chinese French oceanography mission, CFOSAT. SWIM aims at measuring the $2 \mathrm{D}$ oceanic wave spectra; it is a $\mathrm{Ku}$ band real aperture radar.

Simulations are performed to get data along the satellite track: radar signals are obtained simulated interaction with a realistic sea surface and taking into account the radar geometry. Then, the simulated data are processed with software prototypes.
\end{abstract}

Index Terms - Oceanography, radar, CFOSAT, SWIM, wave scatterometer

\section{INTRODUCTION}

The Chinese and French Space Agencies (resp. CNSA and CNES) have proposed to jointly carry out an innovative mission, CFOSAT (China France Oceanography SATellite) devoted to the monitoring of the ocean surface and its related science and applications. Currently under Phase D (manufacturing phase), the launch and the Assessment Phase completion should lead to deliver a fully validated system in orbit in 2018. The primary objective of CFOSAT is to monitor, at the global scale, ocean surface winds and waves. CFOSAT will embark two payloads, SWIM a wave scatterometer provided by France [1], and SCAT a wind scatterometer provided by China [2]. The paper focuses on SWIM data processing. This instrument is a real aperture radar scanning with 6 incidence angles from $0^{\circ}$ to $10^{\circ}$, inherited of the concept described in [3]. The three beams $6^{\circ}, 8^{\circ}$ and $10^{\circ}$ are dedicated to the directional wave spectrum measurements. This spectrum will provide information on energy, propagation direction and wavelength of oceanic waves which wavelengths are between $70 \mathrm{~m}$ and $500 \mathrm{~m}$ with an accuracy step of $15^{\circ}$ in azimuth.

\section{OVERVIEW OF THE PRODUCTS}

The French mission center, CWWIC (CNES Waves and Wind Center) localized at CNES (France) will deliver in near real time the SWIM and SCAT products. Fig.1 illustrates the SWIM products which will be processed at the CWWIC.

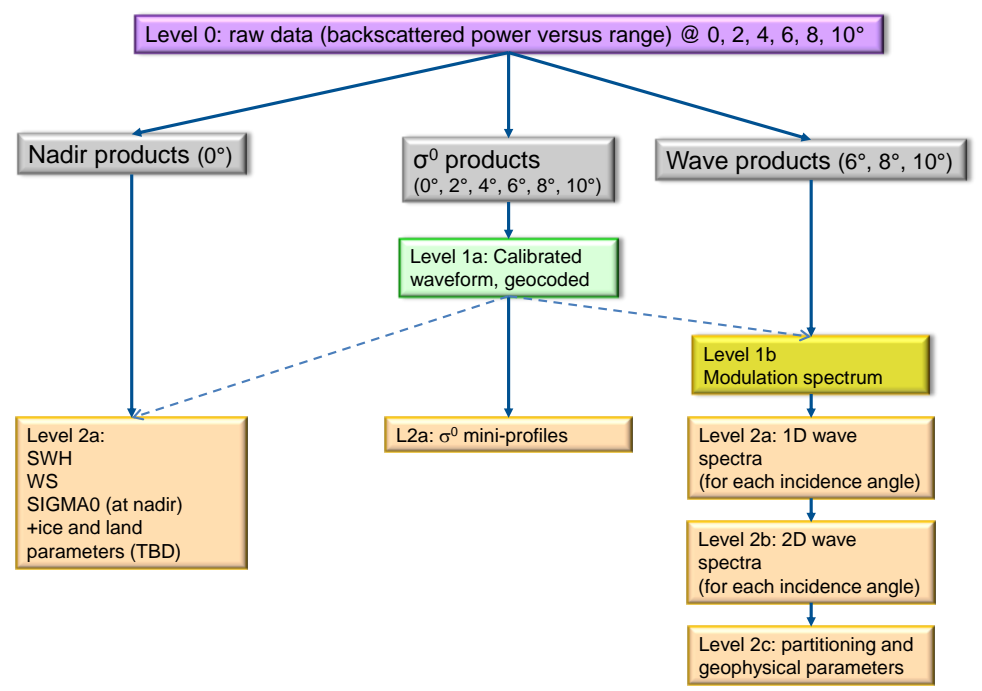

Fig. 1. Overview of the SWIM products from level 0 to level 2.

Three major kinds of products will be made available:

- backscattering coefficient profiles over $\left[0^{\circ}, 11^{\circ}\right]$ of incidence angles,

- nadir significant wave height and wind speed,

- 2D wave spectra and associated geophysical parameters (energy, dominant wavelengths and dominant azimuth) per sea states. 


\section{PROCESSING AND PRODUCTS OF EACH WAVE LEVEL}

\subsection{L1A processing and products}

The level 1a processing will provide calibrated radar echoes from the six beams (normalized radar cross-section in radar geometry), and the associated localization of each range gate (coordinates with respect to nadir track and geographical North). This processing requires the use of calibration parameters provided independently by the processing of the calibration sequences which will be regularly updated. The main steps of the processing are:

- correction by the mean level of thermal noise,

- normalization of the received power to get an averaged power,

- computation of the geometry for each gate (range distance, ground distance from nadir point, elevation, incidence, latitude and longitude),

- inversion of the radar equation taking into account the integrated antenna gain.

In order to test the processing software, a simulation tool, named SimuSWIM has been developed [4]: it enables to generate $\mathrm{L} 0$ data on orbit parts. The inputs are a pre-defined wave spectrum either provided by hindcasts of the wave model MFWAM from the French Meteorological Institute Meteo-France or from empirical spectra wave spectra. Figure 2 and 3 illustrate the level 0 and level 1a products.

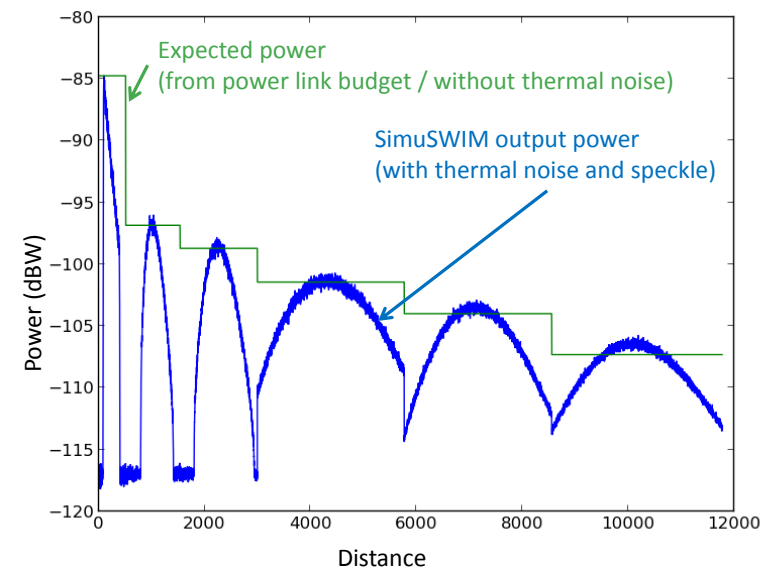

Fig. 2. Example of the LO output power on the six beams (simulation). The blue line is the output power and the green line is the maximal expected power (without thermal noise) from the radar equation.

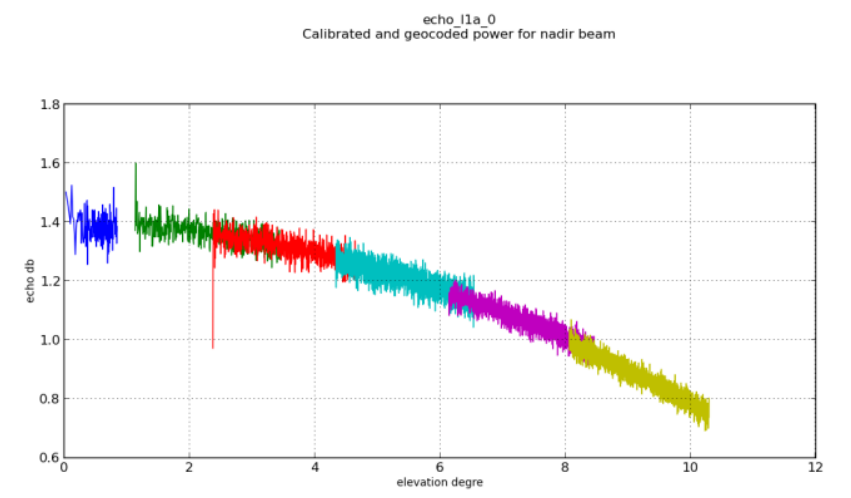

Figure 3: Simulation of Level 1a products for the six SWIM illumination beams: normalized radar cross-section as a function of elevation angles.

\subsection{L1b processing and products}

The L1b products are intermediate products specific of the spectrum beams $\left(6^{\circ}, 8^{\circ}, 10^{\circ}\right)$. They will contain:

- flags on probability of presence of sea ice and rain and flags on the observed mean trend $\sigma 0$ with incidence angle,

- moments of the fluctuations of signal (mean variance, kurtosis, skewness of $\Delta \sigma 0)$ and associated flags,

- density spectra of modulation $\operatorname{Pm}(\mathrm{k}, \mathrm{f})$, corrected from impulse response function and speckle density spectra and provided for each spectrum beam and each azimuth (approximately every $7.5^{\circ}$ in azimuth).

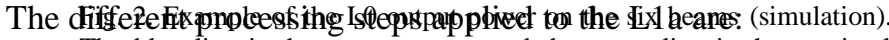

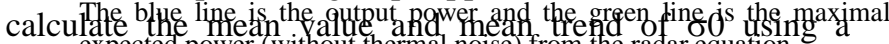
polynomial fit,

calculate the relative fluctuations $\Delta \sigma 0(\mathrm{r})$ around the mean trend, as a function of radial distance,

- resample radial fluctuations to get fluctuations in the surface reference frame $\Delta \sigma^{0}(\mathrm{x})$,

- calculate the fluctuation spectrum,

- calculate the modulation spectrum due to ocean waves by correcting for the impulse response function and for the density spectrum of speckle (the impact of thermal noise is neglected in this step).

Different options for speckle estimation are included in the software [6]. This a major point for investigation in order to estimate the proper level of the modulation spectrum.

Figure 4 illustrates a modulation spectrum for a signal simulated for the $8^{\circ}$ incidence beam. 


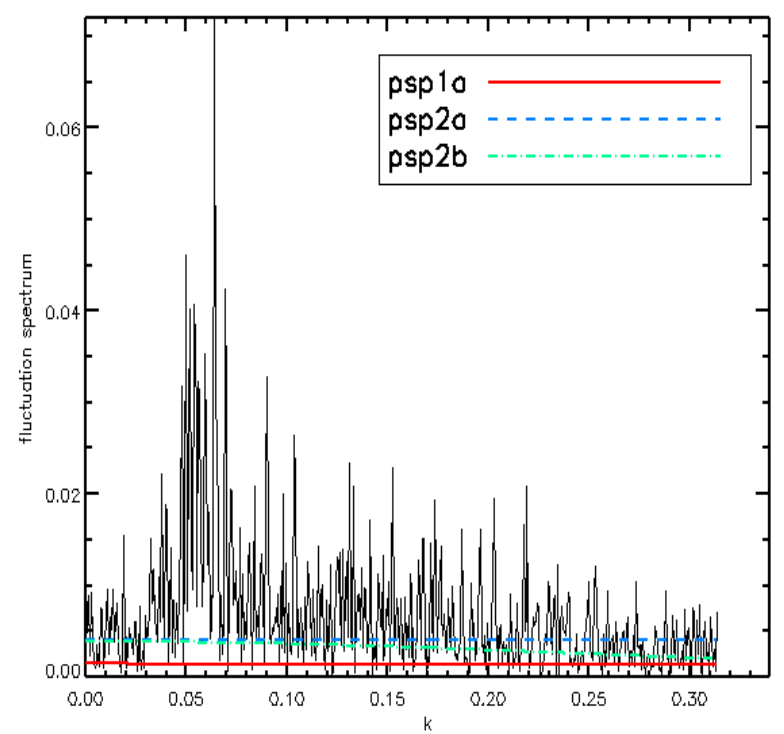

Figure 4: Example of L1b product for a simulated echo obtained with the $8^{\circ}$ incidence beam: density spectrum of signal fluctuations and of speckle with 3 different estimates of speckle spectrum as a function of wave number (in $\mathrm{rad} / \mathrm{m})$.

\section{3. $\mathrm{L} 2$ processing and products}

The Level2 products refer to geophysical data representative of geographic boxes of about $70 \times 90 \mathrm{~km}$. These boxes are defined so as to construct the directional wave spectra by concatenation and fusion of the radial spectra either from a single antenna beam $\left(6\right.$ or 8 or $10^{\circ}$ ) or from the three antenna beams $\left(6,8\right.$, and $\left.10^{\circ}\right)$. For each box, the Level 2 from products the spectrum beams $\left(6^{\circ}, 8^{\circ}, 10^{\circ}\right)$ will contain:

- the directional spectra of wave slopes $(\mathrm{F}(\mathrm{k}, \phi))$ in about 50 wavenumber intervals and 24 azimuth intervals with a $180^{\circ}$ ambiguity in the direction of propagation.

- partitions of the 2D wave spectra, and associated parameters of wave partitions (direction, wavelength, energy);

- mean $\sigma 0$ values as a function of incidence and azimuth.

In addition, products from the nadir processing will be merged to the L2 products (significant wave height, normalized radar cross-section and wind speed.

To construct the Level2 product, the processing steps applied to Level $1 \mathrm{~b}$ products are the following:

- average the modulation spectrum in 50 wave number bins and $15^{\circ}$ azimuth intervals,

- apply the tilt modulation transfer function to estimate wave slope spectra $\mathrm{k}^{2} \mathrm{~F}$,

- apply a partitioning algorithm to detect up to three wave components of the $2 \mathrm{D}$ polar spectrum; the partitioning algorithm is based on the detection of the maxima and a watershed detection [5].

- calculate the main parameters of the 2D spectrum and of its partition (total energy, peak direction, peak wavelength). In order to quantify the accuracy of the Level 2 products, test sets \#1a and \#1b have been used. The errors on the energy $E$, wavelength $\lambda$ and direction $\phi$ are calculated on each partition.

Figure 5 illustrates an example of a simulated 2D and omni-directional wave spectrum contained in the L2 product.
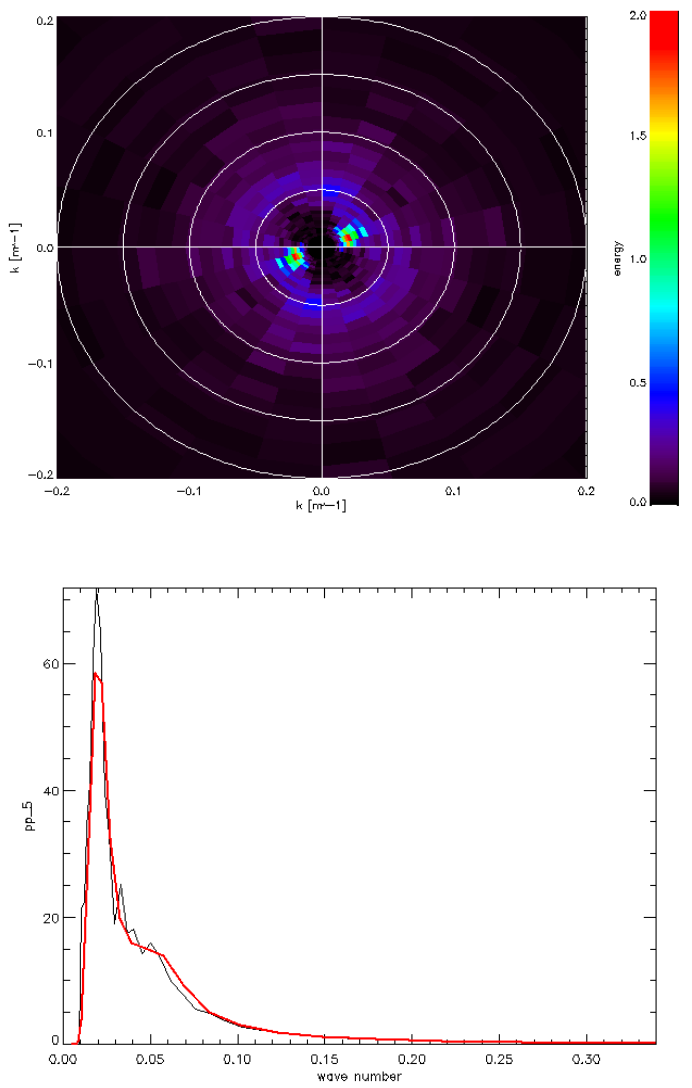

Figure 5: Example of simulated 2D (left) and omnidirectional (right) wave spectrum for a case a high sea state $(\mathrm{Hs}=5.3 \mathrm{~m})$. The black (resp. red) line on the right plot is the simulation (resp. reference)

Figure 6 illustrates the result of a performance analysis based on a simulation of a 10-min of L2 products in a case of high wind and waves. It shows the very good agreement between the inverted products and the reference, except on the energy where a bias can be observed. The energy is the tricky parameter to be estimated and researches are still ongoing to improve its estimation. 

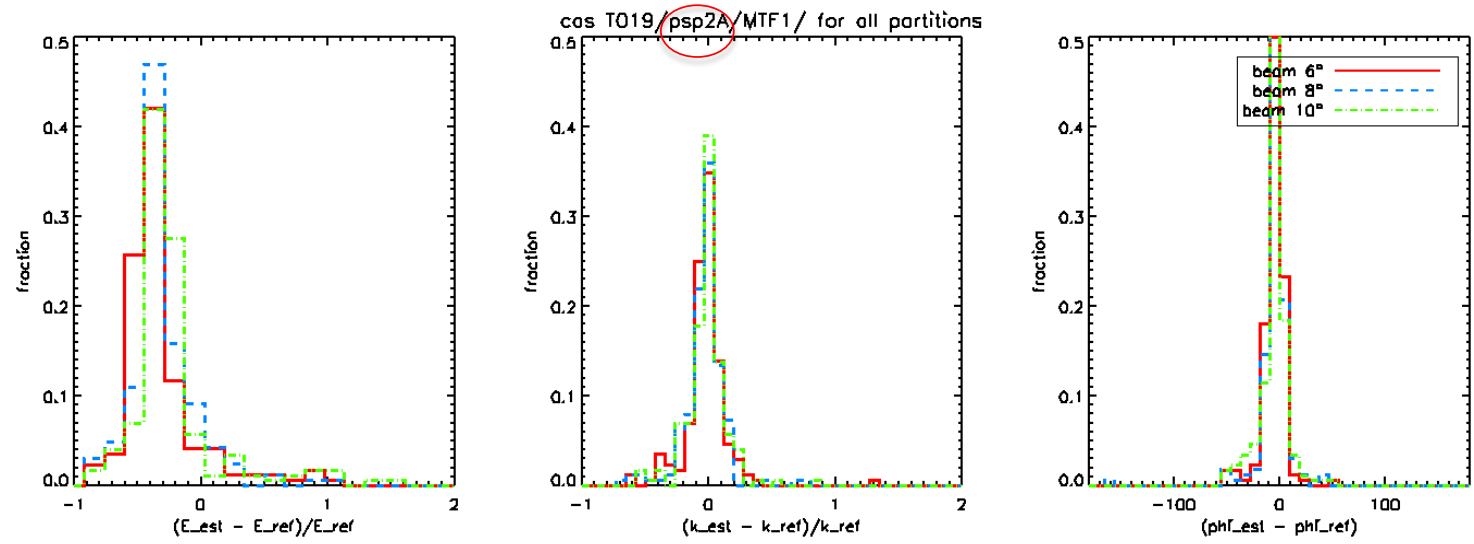

Figure 6: Histograms of relative error on the energy (left), wavelength (middle) and azimuth (right) of the wave spectrum between simulation and reference for 10 minutes of data of the 6,8 and $10^{\circ}$ beams of SWIM. Energy: relative bias $=14-22 \%$, scatter index $=30 \%$; wavelength: relative bias $=1-2 \%$, scatter index $=19 \%$; azimuth direction: relative bias $=1^{\circ}$, scatter index $=10-17^{\circ}$.

\section{CONCLUSION}

The SWIM instrument will provide innovative data (global coverage of directional wave spectrum) which will help for sea state forecast and climate studies. The synergy with the SCAT instrument will be of great interest as for the first time wind and wave will be observed at the very same time. For the present time, the processing algorithms are under definition and tests. Some trade-offs have to be made, mostly on the speckle spectrum estimation and on the tilt modulation transfer function estimation. Several algorithms are implemented and tested on simulated data. All this work will lead to an operational ground segment for the CFOSAT launch.

Synergies between SWIM and SCAT products will be mainly performed at levels 3 and 4 . On French side, these levels are under IFREMER responsibilities. In the levels 1 and 2, we plan to use the SCAT wind product to complete the information provided by the nadir beam. This has not been tested yet. It will be a major research axis for the future as having wind and wave information at the same place is the major innovation of the project.

\section{REFERENCES}

[1] Enjolras V., L. Rey, T. Amiot, C. Tison, P. Castillan, SWIM, a state of the art multi-incidence beams Ku-band waves scatterometer to go beyond current radar systems, in IGARSS'09, July 2009

[2] Zhu J., X. Dong, W. Lin, X. Xu, Calibration and estimation of attitude errors for a rotating fan-beam scatterometer using calibration ground stations, IEEE JSTARS, PP(9), 2014

[3] Hauser, D., Soussi, E., Thouvenot, E., and Rey, L., "SWIMSAT: a real aperture radar to measure directional spectra of ocean waves from space main characteristics and performance simulation”. Jour. Atmos. Oceanic Tech., 18, 2001
[4] C. Tison, T. Amiot, T. Koleck, D. Hauser, P. Castillan, N. Corcoral, L. Rey, E. Caubet, Latest advances of the SWIM instrument, IGARSS'14, July 2014

[5] Hanson J.L. and O.M. Phillips, Automated Analysis of Ocean Surface Directional Wave Spectra., J. Atmos. And Oceanic Tech. vol18, 2001, p 277-293

[6] Hauser D., G. Caudal, R. Valentin, C. Legac, N. Pauwels, A study of speckle properties over the ocean surface from the airborne radar Kuros, ENVIREM workshop, june 2015 